\title{
Data-Augmentation Method for BERT-based Legal Textual Entailment Systems in COLIEE Statute Law Task
}

\author{
Yasuhiro Aoki $^{1} \cdot$ Masaharu Yoshioka $^{1,2,3,4} \mathbb{D} \cdot$ Youta Suzuki $^{1}$
}

Received: 10 September 2021 / Accepted: 7 January 2022 / Published online: 28 February 2022

(c) The Author(s) 2022

\begin{abstract}
A legal textual entailment task is a task to recognize entailment between a law article and its statements. In the Competition on Legal Information Extraction/Entailment (COLIEE), this task is designed as a task to confirm the entailment of a yes/ no answer from the given civil code article(s). Based on the development of deeplearning-based natural language processing tools such as bidirectional encoder representations from transformers (BERT), many participants in the task used such tools, and the best performance system of COLIEE 2020 was a BERT-based system. However, because of the limitation of the size of training data provided by the task organizer, training such tools to adapt to the variability of the questions is difficult. In this paper, we propose a data-augmentation method to make training data using civil code articles for understanding the syntactic structure of the questions and articles for entailment. Our BERT-based ensemble system, which uses this augmentation method, achieves the best performance (accuracy $=0.7037$ ) in Task 4 of COLIEE 2021. We also introduce the results of additional experiments to discuss the characteristics of the proposed method.
\end{abstract}

\section{Introduction}

A legal textual entailment task is a task to check whether a given statement is entailed by the relevant law article(s) and is one of the oldest tasks in the Competition on Legal Information Extraction/Entailment (COLIEE) [3, 4, 11, 12, 16].

\footnotetext{
This paper is an extended and revised version of the following paper. Masaharu Yoshioka, Yasuhiro Aoki, and Youta Suzuki. 2021. BERT-based ensemble methods with data augmentation for legal textual entailment in COLIEE statute law task. In Proceedings of the Eighteenth International Conference on Artificial Intelligence and Law (ICAIL '21). Association for Computing Machinery, New York, NY, USA, 278-284 https://doi.org/10.1145/3462757.3466105.
}

This work was partially supported by JSPS KAKENHI Grant Number 18 H0333808.

Masaharu Yoshioka yoshioka@ist.hokudai.ac.jp

Extended author information available on the last page of the article 
R02-36-E (Answer: not entail)

Question

\begin{tabular}{|c|c|}
\hline $\begin{array}{l}\text { 共有者の一人である Aが共有物について他の共有 } \\
\text { 者であるBに対して有する債権は，Bの特定承継 } \\
\text { 人に対しては, 行使することができない。 }\end{array}$ & $\begin{array}{l}\text { A claim that a co-owner }(A) \text { holds against } \\
\text { another co-owner }(B) \text { with respect to the } \\
\text { property in co-ownership may not be exercised } \\
\text { against B's specific successors. }\end{array}$ \\
\hline \multicolumn{2}{|c|}{ Article } \\
\hline $\begin{array}{l}\text { 二百五十四条 共有者の一人が共有物について } \\
\text { の共有者に対して有する債権は、その特定承継 } \\
\text { に対しても行使することができる。 }\end{array}$ & $\begin{array}{l}\text { Article } 254 \text { A claim that one of the co-owners } \\
\text { holds against other co-owners with respect to } \\
\text { the property in co-ownership may be exercised } \\
\text { against their specific successors. }\end{array}$ \\
\hline
\end{tabular}

Fig. 1 Example of a question and article pair for COLIEE legal textual entailment tasks

In COLIEE 2021 [10], Task 4 is a legal textual entailment task that uses Japanese Bar exam questions and civil code articles. Figure 1 is an example of this question and article pair.

To solve this entailment problem, it is necessary to recognize two different relationships between questions and the given articles. One is a relationship based on the logical structure, and the other is a semantic relationship between the words used in the questions and the ones used in the articles. In the early stage [4], analysis results of natural language processing (NLP) tools (e.g., morphological parser and syntactic parser) were used with pattern-based or machinelearning-based systems to identify the former relationship. For handling the latter relationship, machine-readable thesauruses such as WordNet [7] and distributed representation of words such as Word2Vec [6] were used. Recently, the development of deep-learning-based NLP tools enables dealing with both relationships at once. For example, bidirectional encoder representations from transformers (BERT) [1] is a tool that can analyze semantic context and solve classification problems such as the identification of entailment and relevancy of queries and documents. One of the characteristics of BERT is that it provides a general semantic analysis system that can be fine-tuned for a particular task. In COLIEE 2020 [11], a BERT-based system achieved the best performance in the statute law legal article information retrieval task [13] and the entailment task [9]. However, because of the small size of the training data, the best performance system of the entailment task [9] used a large volume of legal texts that were not directly related to the statute law task.

To solve this training data size problem, we propose a data-augmentation method to increase the training data using original civil law articles. This method generates article-and-question pairs systematically. For COLIEE 2021, we also propose a BERT-based ensemble system for legal textual entailment that uses training data provided by organizers and our augmented data for training. This system achieved the best accuracy (0.7037) in COLIEE 2021 Task 4. We also conduct additional experiments to understand the characteristics of the system.

The rest of this paper is divided into the following sections. Section 2 introduces related works, and Sect. 3 introduces our data-augmentation method and BERT-based ensemble legal textual entailment system. Section 4 demonstrates 
our system using COLIEE Task 4 submission results and additional experiments, and Sect. 5 concludes the paper.

\section{Related Works}

Because bar exam questions include questions about real use cases of articles, it is necessary to discuss the correspondence between the concepts used in the articles and real use cases. In the early stage of COLIEE, several attempts were made to utilize resources for discussing such semantic matching, such as a machine-readable thesaurus and data for the distributed representation of the terms. For example, Mi-Young et al. [5] used Word2Vec [6] as a resource for distributed representation, and Taniguchi et al. [15] proposed a method to utilize WordNet [7] as a machinereadable thesaurus. However, because those methods cannot handle the context to determine the meaning of such terms, they are not so effective for utilizing such resources.

Recently, Devlin et al. [1] proposed BERT, a deep-learning-based NLP tool that is pretrained for general semantic recognition tasks with larger corpora (such as the whole contents of Wikipedia). Based on this training process, BERT can handle the meaning (distributed representation) of words in a sentence by considering the context. In addition, BERT can be used for various tasks by employing a fine-tuning process that utilizes comparatively smaller numbers of training data. Because a pretrained model of BERT contains rich information about the semantics of the words, the fine-tuned models may be able to handle semantic information even though the words themselves are not included in the training data.

In COLIEE 2020, the BERT-based system achieved the best performance for legal textual entailment tasks (JNLP [9]). In that paper, they proposed a lawfulness classification approach that classified the appropriateness of legal statements using many legal sentences that include bar exam questions provided by organizers without considering given relevant articles. This approach worked well for COLIEE 2020 because of the large number of training data. In addition, they also pointed out that it was difficult to select an appropriate model using validation data for the unseen questions because of the significant variability of the questions.

To increase the size of the training data, the data-augmentation approach is widely used in the field of image recognition [14]. However, few studies related to the data-augmentation method have been conducted for legal textual entailment tasks. Min et al. [8] proposed a syntactic-based data augmentation method to increase the robustness of natural language inferences. They also proposed a systematic method to create positive and negative data from the correct inference sentence by a syntactic operation such as passivation and the inversion of subject and object. Evans et al. [2] proposed a method for data augmentation for logical entailment. In this framework, their method increased negative and positive data by modifying logical inference rules using symbolic vocabulary permutation, including an operation to make implication rules that share the same contents for the condition and derived parts. Those approaches are useful to design data-augmentation methods for legal textual entailment. 


\section{BERT-based Ensemble Legal Textual Entailment System}

Based on a discussion of the previous best performance system (JNLP [9]), we propose a system with the following characteristics.

1. Textual entailment approach with data augmentation

We assume that the reason why the lawfulness classification approach outperformed the textual entailment one in the last COLIEE is the size of the training data. Therefore, when we provide larger training data by data augmentation, the textual entailment approach may outperform the lawfulness classification approach because it uses the most important information (relevant articles).

2. Ensemble results of multiple BERT-based model outputs

As discussed, it is difficult to select appropriate models for the task by only evaluating the validation model. From our preliminary experiment (the details are discussed in Sect. 4.2), we confirmed that the characteristics of fine-tuned BERT-based models are different and that the accuracy of the validation data is not directly related to that of the test data. We assume that this result reflects the different characteristics of each model and that the appropriate selection of the generated models for ensemble may improve the performance for the unseen questions.

\subsection{Data Augmentation using Articles}

In the deep learning framework, it is common to enlarge training data by modifying the existing data (data augmentation). However, it is important to define the appropriate data-augmentation method to obtain the best results. Related to the legal textual entailment task, data-augmentation methods have been used for natural language and logical inference, as introduced in Sect. 2. However, it is difficult to apply these methods to these legal textual entailment data.

In this study, we assume that there are two types of errors to judge whether an article entails a given question. One is a semantic mismatch and the other is a logical mismatch (the appropriateness of the judicial decision).

For example, let us discuss the example of training data using the following article (a part of article 9): "A juridical act performed by an adult ward is voidable."

1. "A juridical act performed by an adult is voidable."

The article does not entail this question because of semantic matching ("adult" is not "adult ward").

2. "A juridical act performed by an adult ward is not voidable."

The article does not entail this question because of the inappropriateness of the juridical decision ("voidable" and "not voidable")

3. "A juridical act performed by an adult is not voidable."

We cannot judge whether this question is true (it may require another article). However, a given article cannot entail the question. 
For the semantic matching case (1), it is difficult to select appropriate pairs ("adult" and "adult ward") for replacement to make such a semantic mismatch sentence. For both cases (3), it is also difficult to make the data and to use these data for negative examples to identify types of errors to judge the entailment results.

By contrast, if we make the pair of correct answers with logical mismatch cases (2), the examples may help to explain the importance of comparisons between the judicial decision of the article and that of the question.

In the bar exam questions, there are questions to check whether the candidates understand the article appropriately. This type of question uses almost identical sentences from the article or one that flipped the juridical decisions of the original sentence. This may suggest that it is easy to construct augmented data using sentences about juridical decisions in the article automatically. On the contrary, it is not so easy to use golden standard data (question and article pairs). For the negative examples (No: not entail), it is not easy to make appropriate corresponding positive (Yes: entail) questions because it includes all three types (1-3) of mismatch. For the positive examples, even though we made negative examples by flipping the juridical decision for case (2), it can be treated as a mismatch case (3) when the system fails to make mapping between the condition part of the questions and articles. Therefore, we decided to use article data only as a resource for data augmentation.

For the automatic construction of augmented data using articles, simple separation of sentences using end-of-sentence markers ("。”:period) and paragraphs is not appropriate because there are sentences that refer to previous juridical decisions, conditions, or lists of cases that apply the previous juridical decisions. Thus, we propose a method to generate sentence pairs from articles that follows a three-step process.

\section{Identify the logical structure of a sentence}

Most of the articles may contain texts for representing juridical decisions and lists of conditions for the case where such decisions may apply. This process classifies the sentence parts and lists of condition parts.

\section{Generate sentences for augmentation}

Texts for juridical decisions are split into sentences using end-of-sentence markers and paragraph information. Sentences that refer to juridical conditions and/or decisions are expanded using information in the previous sentence. A list of condition parts is used for expanding a sentence that refers to this list.

3. Make augmentation data

All generated sentences are used for making augmented data. For the positive data, each sentence from the generated data is used for both question and article parts. For the negative data, we use sentences that flip the juridical decision for the question parts. 


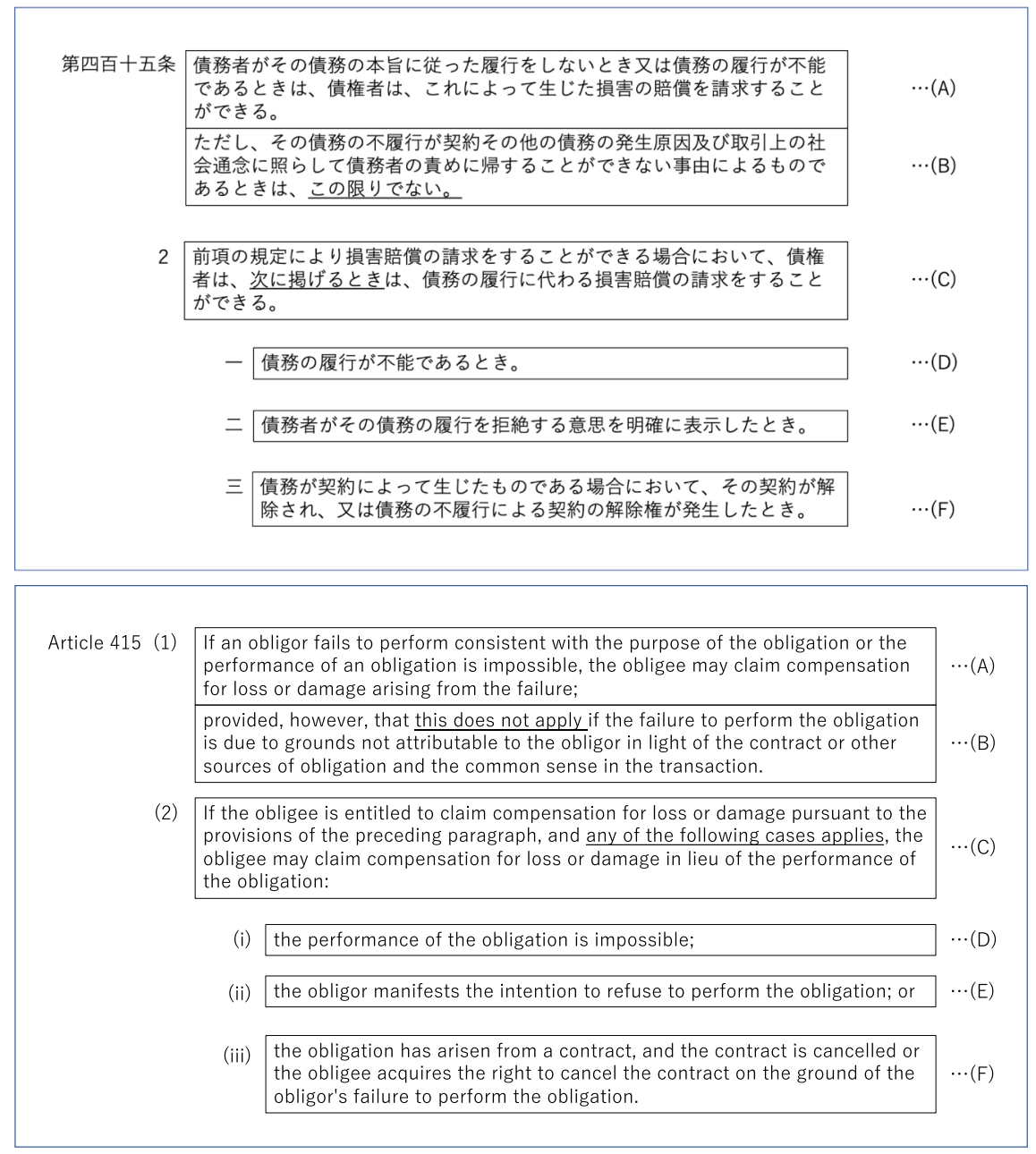

Fig. 2 Examples of identification of sentences (Japanese/English)

Details of this process can be summarized as follows.

\section{Identification of logical structures}

Most of the articles may contain texts for representing juridical decisions and lists of conditions for the case where such decisions may apply. Figure 2 shows an example of an article to explain this identification process. Most of the texts are selected as sentences by splitting the texts using end-of-sentence markers and paragraph information ("A"-"F"). A list of cases is described using an enumerated list using numbers (“-”(i) and “二”(ii), “三”(iii), , ). As a result, we obtain three sentences ("A"-"C") and one condition list ("D"-"F"). These condition list parts are merged with a sentence that refers to this condition list. For this case, 
Sentence $\mathrm{C}$ (just before the condition list) refers to the condition list using the phrase “次に掲げるとき” (“any of the following cases apply”).

2. Generating sentences for data augmentation

In this step, we generate sentences that contain juridical decisions and conditions. Most sentences have both parts in a sentence, but several exceptional cases refer to other parts of the text. The following are types of such omissions with an explanation of how the system modifies such sentences to generate ones that have decision and condition parts in a sentence.

- Omission of juridical decision for the other case or exceptional case

Some sentences refer to juridical decisions in the previous sentence with a particular style. One is “同様とする” (“the same applies”), referring to the same decision; and the other is “この限りでない” (“this does not apply”), referring to the flipped decision. Those parts are replaced using the juridical decision in the previous sentence. For the latter case, flipped decision is used for the replacement $((\mathrm{A}+\mathrm{B})$ in Fig. 3).

- Omission of conditions for juridical decisions

Some sentences refer to the conditions of previous sentences. There are two types of references. One is referring to previous texts using an article number or a previous sentence. The other is a reference to the list of conditions. For the former type, we replace a reference to the previous sentence (“この)場合 において”" (“In this case”)) only by using condition parts of the previous sentence. For the latter case (“次に掲げる場合”(“In the following cases”)), we replace these parts using referred condition parts. When there are two or more conditions (e.g., reference to the condition list), we generate a sentence for each condition ((C'), (C"), (C'”) in Fig. 3).

In addition, to make the sentence simpler for making better training data, additional information such as “*の規定にかかわらず” (“Notwithstanding”) and other information such as terms in a bracket (e.g., metadata, paraphrasing of terms) are removed from the sentences.

\section{Making training data}

For the positive data, all sentences generated in the last step are used for making positive samples by using both for question and article parts. For the negative examples, we flip the juridical decision parts of the sentences using manually constructed pattern-based matching (e.g., adding or removing “ない” (not) for the verbs, and replacing terms with antonyms (“有効” (effective) and “無効” (ineffective))). However, when there is no appropriate expression for juridical decisions in a sentence, no negative example is generated by the system. Pairs of a negative sentence and an original sentence are used for question and article parts, respectively.

Using this procedure, we construct 3,351 (positive: 1,687, negative: 1,664) training examples for data augmentation. However, the data are not exactly the same as the data used for the COLIEE 2021 submission because of bugs in the dataaugmentation program used for the submission. The total number of augmented data used for the submission was 3,331 (positive: 1,677, negative: 1,654), and 


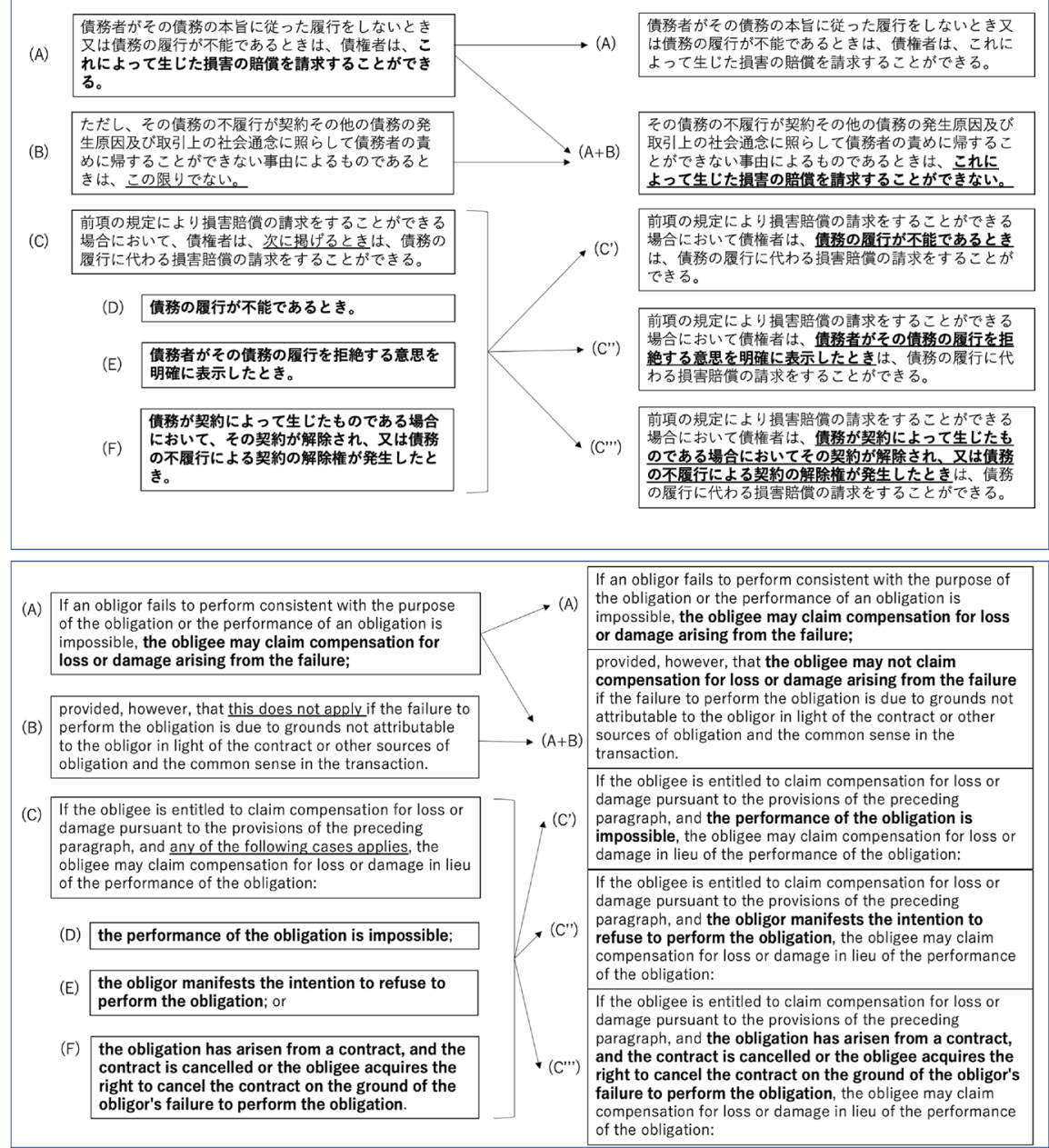

Fig. 3 Examples of generating sentences for data augmentation (Japanese/English)

2,540 data are the same as the generated ones. The most significant difference between the data generated by this procedure and the submitted one is the treatment of antonyms. For example, the previous program generates “無効としな い” (“is not ineffective”) as a negative example for “無効とする” (is ineffective). However, the new program generates “有効とする” (“is effective”) by using an antonym dictionary. Former sentences are not appropriate for the human reader, but it may not be a big problem for the BERT used in the submission system to identify the logical mismatch. 
The programs for generating augmented data and other information related to this experiment including experimental settings are available from https://wwwkb.ist.hokudai.ac.jp/COLIEE-DA/.

\subsection{Ensemble Methods using BERT-based Entailment Systems}

We implemented a BERT-based entailment system using the ordinal BERT fine-tuning process proposed in [1]. We concatenated the question and article using a sentence-separator token ([SEP]) and fed it into the BERT model to estimate whether the article entails a question (positive: 1) or not (negative: 0). We use the BERTbased model of BERT-Japanese. ${ }^{1}$

Fine-tuned models accept a pair of question statements and (an) article(s) as input and return whether the article(s) entail the statement using the score ( 0 to 1 ) for the probability of being positive or negative. When the score is larger than 0.5 , the system selects the pair as positive (Yes: entail). For other cases, the pair is selected as negative (No: not entail).

From the preliminary experiments (the details are discussed in Sect. 4.2), we confirmed that there is no significant correlation between the accuracy of validation data and the accuracy for test data, reflecting the variability of the questions (difference between validation set and test set). Therefore, it is difficult to select an appropriate model that can estimate the unseen questions well.

To reduce the effect of this variability, we propose to use the ensemble learning framework to merge system outputs. Because of the nondeterministic characteristics of the BERT fine-tuning process and different data sets, we expected that the trained models might focus on different features for analyzing the texts. As a result, these systems may have types of questions where they can estimate answers with higher confidence (the score is close to 0 or 1 ) or one with little confidence (the score is close to 0.5 ). Therefore, we use the average score of the pair calculated by the system for the final output of the ensemble models instead of using simple majority voting because this score shows the confidence of the system for the answer.

In such a framework, the selection of appropriate ensemble model sets may correspond to the selection of model sets that work in a complementary manner (the system mostly uses estimated results with higher confidence). Therefore, we propose to use an additional validation data set to select such model sets.

Based on the presented discussion, we propose an ensemble method that uses multiple BERT-based entailment systems with different training settings as the following two steps.

\footnotetext{
${ }^{1}$ https://github.com/cl-tohoku/bert-japanese with model https://huggingface.co/cl-tohoku/bert-basejapanese-whole-word-masking.
} 
1. Training of BERT-based entailment model with different training and validation data.

Considering the variability of the questions, we constructed multiple BERT models using different training and validation data that are constructed randomly.

2. Selection of an appropriate ensemble model set using additional validation data.

For selecting the appropriate model sets as combinations of previously constructed models, we used additional validation data for the selection process. The system produces estimated results using additional validation data. Ensemble results of all possible combinations of these models are generated by calculating the average score of the used models. Those sets are evaluated by the validation data, and the ones with the best performance (or top-ranked ones) are selected as candidate ensemble model sets.

\section{Legal Textual Entailment Experiment}

\subsection{COLIEE 2021 Submission System}

For the legal textual entailment task of COLIEE 2021, organizers provided training data constructed from 14 years (2006-2019) of bar exam questions data. From this data set, we decided to use data constructed from the latest year (2019: 111 questions) as validation data for analyzing appropriate ensemble model sets because this data set is used for the evaluation of COLIEE 2020. Therefore, we can easily compare the performance of our proposed system with the ones developed for COLIEE 2020. For the training of a BERT-based entailment system, we used 13 years of data (695 questions).

This original data set was randomly split 90\% (625) for training and 10\% (70) for validation. We constructed 10 different training and validation sets to make different BERT models. In addition to the training data constructed from the original data, all augmented data $(3,331$ examples for the submission system) were merged with the training data. As a result, we used 3,956 examples for training and 70 for validation. We also made training sets without using augmented data (625 training and 70 validation examples) to compare system performance without augmented data.

One of the important parameters for the BERT is a max sequence length. If the sequence is too short, it is difficult to obtain appropriate results because the information that appears after the max sequence cannot be used for the analysis. Therefore, we analyzed the sequence length of all question and article pairs to determine the appropriate sequence length.

Figure 4 shows the information of the sequence length for the training data of COLIEE 2021 and the augmented data (total 4,137 pairs). The examined sequences include the CLS token and SEP token that are used for representing class (Yes: 1 and No: 0) and separator (split texts into two parts: question and articles), respectively.

From this graph, we confirmed that most pairs have a sequence length less than 256 (98.38\%). Consequently, we decided to use a max sequence length of 256 by considering the efficiency of the training process. 


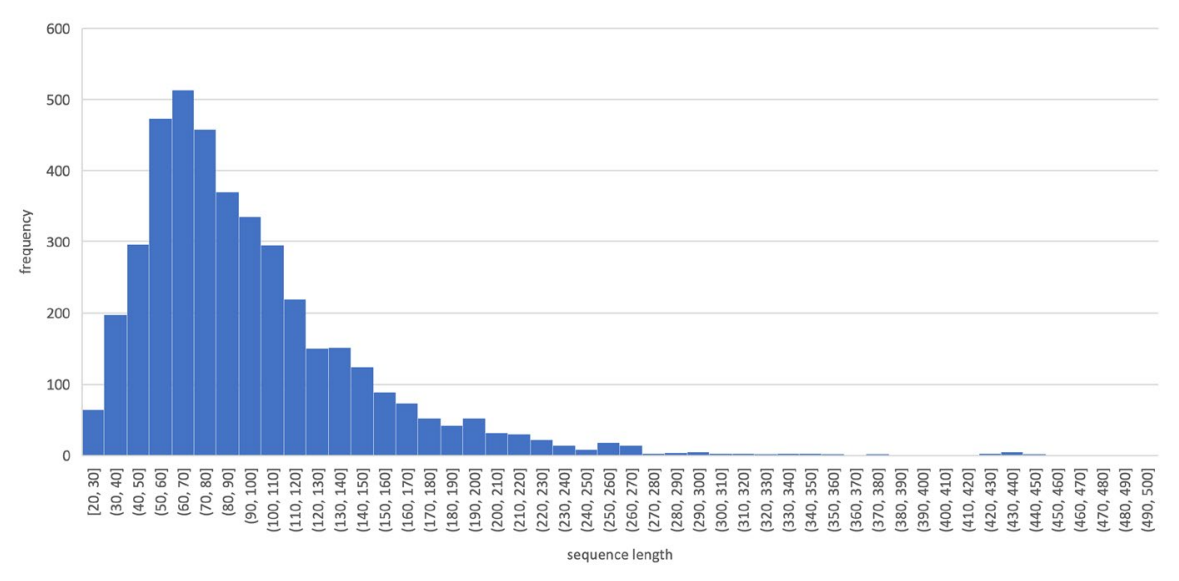

Fig. 4 Training data sequence length

In addition, the fine-tuning of the BERT model is done using Adam as an optimizer, cross entropy as the loss function, a training batch size of 12 , and a learning rate of 1e-5. The validation loss is calculated at each epoch and stop-training process when the validation loss increases. We used a model with minimal validation loss. Details of the experimental settings including the parameters for the training process, a list of questions used for each training process is also available from https:// www-kb.ist.hokudai.ac.jp/COLIEE-DA/.

The fine-tuning process converged quickly, and the validation loss at the end of one epoch was the smallest in most cases. One epoch took less than 160 seconds, making it fast to train. This short computation time will be advantageous when increasing the number of models in the ensemble and when increasing the number of data to be trained.

\subsection{Preliminary Experiments}

In the first experiment, we compared the system performance of the one that used both original training data and augmented data with the one that used original training data only. For the original training data, we used 10 different training and validation sets constructed in Sect. 4.1 and evaluated the performance of the system using the R1 data set (111 questions for validation data for analyzing appropriate ensemble mode) as test data.

Table 1 shows the evaluation results for the validation and test data with different models. Numbers with bold font and ones with italic show the best and worst results among the 10 models, respectively. As shown in the table, augmented data are helpful to improve the performance of BERT-based entailment systems. Detailed comparison of these two systems is discussed in Sect. 4.6. In addition, we also confirm that the validation accuracy and loss were not closely related to the test accuracy. We assume that these results reflect the variability of the question set. 
Table 1 Evaluation results of the 10 models

\begin{tabular}{|c|c|c|c|c|c|c|}
\hline \multirow[b]{2}{*}{ Model no. } & \multicolumn{3}{|c|}{ Training data only } & \multicolumn{3}{|c|}{ With augmented data } \\
\hline & $\begin{array}{l}\text { Validation } \\
\text { loss }\end{array}$ & $\begin{array}{l}\text { Validation } \\
\text { accuracy }\end{array}$ & Test accuracy & $\begin{array}{l}\text { Validation } \\
\text { loss }\end{array}$ & $\begin{array}{l}\text { Validation } \\
\text { accuracy }\end{array}$ & Test accuracy \\
\hline 1 & 0.6818 & 0.5714 & 0.5225 & 0.6935 & 0.4857 & 0.5946 \\
\hline 2 & 0.6481 & 0.6286 & 0.4775 & 0.7247 & 0.5286 & 0.6667 \\
\hline 3 & 0.6934 & 0.5143 & 0.5045 & 0.7566 & 0.6286 & 0.6486 \\
\hline 4 & 0.6951 & 0.5429 & 0.5045 & 0.6822 & 0.6286 & 0.6486 \\
\hline 5 & 0.6922 & 0.5286 & 0.4677 & 0.7347 & 0.5143 & 0.6486 \\
\hline 6 & 0.6923 & 0.5571 & 0.5315 & 0.7745 & 0.6143 & 0.6396 \\
\hline 7 & 0.6741 & 0.6286 & 0.5586 & 0.6913 & 0.5429 & 0.6126 \\
\hline 8 & 0.7155 & 0.4571 & 0.4595 & 0.7123 & 0.5857 & 0.6486 \\
\hline 9 & 0.6882 & 0.4857 & 0.5315 & 0.7504 & 0.6286 & 0.6486 \\
\hline 10 & 0.6806 & 0.5714 & 0.5135 & 0.7735 & 0.5857 & 0.6396 \\
\hline
\end{tabular}

Table 2 Evaluation results of the ensemble models

\begin{tabular}{ll}
\hline Model used & Accuracy \\
\hline$(1,2,3,4,5,6,7)$ & 0.694 \\
$(1,2,4)$ & 0.689 \\
$(1,2,3)$ & 0.685 \\
$(1,2,3,4,7)$ & 0.682 \\
$(1,2,6)$ & 0.676 \\
$(1,2,5)$ & 0.676 \\
$(1,2,3,4,5,7)$ & 0.676 \\
$(1,2,3,4,5,6)$ & 0.676 \\
$(1,2,3,4,5)$ & 0.676 \\
$\cdots$ & $\cdots$ \\
$(1,2,3,4,5,6,7,8,9,10)$ & 0.622 \\
\hline
\end{tabular}

These 10 models with augmented data were used for selecting the appropriate ensemble model sets. For the COLIEE 2021 submission, we checked the model sets that used three or more models for the evaluation. Table 2 shows the evaluation results of these ensemble model sets by accuracy.

There were large differences between the accuracy of the ensemble cases. The best accuracy system ensembled seven models, and the worst used all models. Most of the cases that used three to five models were adequate to estimate the results with better accuracy.

All of the highest rank sets contained the best performance system model 2. In addition, they also used model 1, even though the accuracy of model $\mathbf{1}$ was the lowest among these 10 models. This suggests that it is important to use a complementary set of models that have different characteristics to improve the overall performance of the ensemble models. 
Table 3 Ensemble model settings for the submission

Table 4 Final evaluation results

Table 5 Evaluation results of the 10 models for the test data

\begin{tabular}{lll}
\hline Submission ID & Correct & Accuracy \\
\hline BaseLine & No 43/All 81 & 0.5309 \\
HUKB-2 & 57 & 0.7037 \\
HUKB-1 & 55 & 0.6790 \\
HUKB-3 & 55 & 0.6790 \\
UA_parser & 54 & 0.6667 \\
JNLP.Enss5C15050 & 51 & 0.6296 \\
OVGU_run3 & 48 & 0.5926 \\
TR-Ensemble & 48 & 0.5926 \\
KIS1 & 44 & 0.5432 \\
\hline
\end{tabular}

\begin{tabular}{ll}
\hline Model no. & Accuracy \\
\hline 1 & 0.6790 \\
2 & 0.6666 \\
3 & 0.5185 \\
4 & 0.5555 \\
5 & 0.6666 \\
6 & 0.5308 \\
7 & 0.6790 \\
8 & 0.5925 \\
9 & 0.5555 \\
10 & 0.5308
\end{tabular}

\subsection{Submitted Results}

Based on the results of the preliminary experiments, we submitted the following three results that used different model sets for the ensemble for COLIEE 2021 (Table 3).

HUKB-1 and HUKB-2 were the best and second-best performance systems, respectively, using R1 data as a kind of validation data. HUKB-3 selected the five best models using validation loss information.

Table 4 shows the final evaluation results of our submission runs and the best accuracy runs of each team, among which, HUKB-2 achieved the highest accuracy. 
Table 6 Number of questions classified by the ensemble results

\begin{tabular}{|c|c|c|c|c|c|c|}
\hline \multirow{2}{*}{$\begin{array}{l}\text { Submission } \\
\text { ID }\end{array}$} & \multicolumn{2}{|l|}{ Agree } & \multicolumn{2}{|l|}{ Majority } & \multicolumn{2}{|l|}{ Other } \\
\hline & Correct & Wrong & Correct & Wrong & Correct & Wrong \\
\hline HUKB-1 & 17 & 4 & 27 & 14 & 11 & 8 \\
\hline HUKB-2 & 28 & 9 & 23 & 11 & 6 & 4 \\
\hline HUKB-3 & 19 & 9 & 17 & 12 & 19 & 9 \\
\hline
\end{tabular}

\subsection{Detailed Analysis of the Submitted Results}

To understand the effect of the ensemble method, we compared the performance of the ensemble results with that of each model. Table 5 shows the evaluation results for the 10 models. This year, the basic model performed well, and the best performance systems were almost equivalent to the ensemble ones. However, the appropriate selection of the models (HUKB-2) made the ensemble results better than that for each model.

These results justify the appropriateness of using the ensemble method by selecting an appropriate ensemble set using validation data.

Table 6 shows the number of questions classified by agreement level among the models used. "Agree", "Majority", and "Other" represent "all models return the same results", "final results are the same as majority voting", and others, respectively. From these results, we can confirm that the average calculation ensemble method is better than majority voting because the number of correct questions for others is larger than the number of wrong ones. For the "Agree" questions, the best performance system (HUKB-2) had the largest numbers because of the small number of used models (three), but the accuracy of HUKB-1 (using seven models) for "Agree" was better than that of HUKB-2. However, the accuracy of HUKB-3 was lower than that of HUKB-2, suggesting that selecting an appropriate set of models for the ensemble is also effective for maintaining the accuracy of the "Agree" questions.

\subsection{Additional Experiment with Different Sizes of Fine-Tuned Models}

One of the parameters that is not discussed well for the COLIEE 2021 submission system is the number of candidate fine-tuned models ( 10 for the submission system). So, we would like to discuss the effect of this number by conducting additional experiments that change this value. From this experiment, we used augmented data generated by the procedure explained in Sect. 3.1 (3,351 examples) for making BERT fine-tuning models.

We made 20 randomly split training and validation data using the same method introduced in Sect. 4.1 and conducted experiments using the same procedures. Table 7 shows the accuracy of these models evaluated using the R1 data set (same as test accuracy in Table 1) and R2 data set (same as test accuracy in Table 5). Lines are sorted by the accuracy of Test (R1). The best and worst performances for Test (R2) are shown as numbers with bold font and ones with italic, respectively. The 
Table 7 Evaluation results of the 20 models

\begin{tabular}{llllll}
\hline Model no. & $\begin{array}{l}\text { Test (R1) accu- } \\
\text { racy }\end{array}$ & $\begin{array}{l}\text { Test (R2) accu- } \\
\text { racy }\end{array}$ & Model no. & $\begin{array}{l}\text { Test (R1) accu- } \\
\text { racy }\end{array}$ & Test (R2) accuracy \\
\hline 8 & 0.7117 & 0.5802 & 18 & 0.6577 & 0.6543 \\
3 & 0.7027 & 0.6790 & 6 & 0.6486 & 0.6543 \\
16 & 0.6847 & 0.6914 & 9 & 0.6486 & 0.6173 \\
4 & 0.6757 & 0.6790 & 17 & 0.6486 & 0.5679 \\
7 & 0.6667 & 0.6790 & 1 & 0.6396 & 0.6914 \\
10 & 0.6667 & 0.6790 & 15 & 0.6396 & 0.6420 \\
13 & 0.6667 & 0.5926 & 19 & 0.6306 & 0.5926 \\
14 & 0.6667 & 0.7037 & 2 & 0.6216 & 0.6914 \\
5 & 0.6577 & 0.5062 & 12 & 0.6216 & 0.5679 \\
11 & 0.6577 & $\mathbf{0 . 7 2 8 4}$ & 20 & 0.6036 & 0.6667 \\
& & & Average & 0.6559 & 0.6432 \\
\hline
\end{tabular}

average accuracy for Test (R2) (submission data) is 0.6432 , which is equivalent to the second and third rank in the submission. However, because of the variability of the question and nondeterministic characteristics of the BERT model, we have a model that is better than our best submission system (model 11) and one that is below the baseline. It is better to have appropriate methods to obtain more stable results.

Table 8 shows the list of selected results for all possible combinations of the 20 models as candidate ensembled model sets. The best performance set $(3,6,8,15)$ for Test (R2) (0.6543) was slightly worse than our submitted system and lower than the second-best team (UA) result in Table 4. However, the average performance of the second-best performance sets (five sets) is 0.6765 , which is similar to the score for the submitted results, and the highest accuracy (0.7160) was better than the submitted one. However, because of the effect of generating correct answers by chance and the difficulty in selecting the best performance model set from them, the highest value may not have as much meaning. Comparing the performance of the single model cases, the average is better than the average of the single model cases with more stable results (0.6296-0.7160). In addition, for these model sets, the performance using all models is good for Test (R2), but the performance for Test (R1) is not so good. Because those values for accuracy may reflect the variability of questions for R1 and R2, it is better to select an appropriate set of models rather than using all ensembled models.

Based on this analysis, we confirmed that adding more models may increase the possibility to include models with higher consistent accuracy and/or a set of models that work in a complementary manner. However, increasing the number of such a set may result in over-fitting to the test data ( $\mathrm{R} 1$ for this case) for selecting ensemble model sets. For example, from the second-best performance sets, ensemble sets with six models $(3,8,10,13,16,18)$ do not work well for the Test $(\mathrm{R} 2)$. It is necessary to take into account such effects for considering the appropriate setting for generating these models and selecting the appropriate ensemble model set. 
Table 8 Evaluation results of the ensemble results using 20 models

\begin{tabular}{|c|c|c|}
\hline Model no. & Test (R1) accuracy & Test (R2) accuracy \\
\hline \multicolumn{3}{|l|}{ Best accuracy for Test (R1) } \\
\hline$(3,6,8,15)$ & 0.7658 & 0.6543 \\
\hline$(3,4,8,11,17)$ & 0.7477 & 0.7160 \\
\hline$(3,9,11,17,20)$ & 0.7477 & 0.7037 \\
\hline$(3,4,8,13,20)$ & 0.7477 & 0.6790 \\
\hline$(3,6,8,16)$ & 0.7477 & 0.6543 \\
\hline$(3,8,10,13,16,18)$ & 0.7477 & 0.6296 \\
\hline \multicolumn{3}{|l|}{ Using all models } \\
\hline$(1,2, \ldots, 20)$ & 0.6486 & 0.6790 \\
\hline \multicolumn{3}{|l|}{ Worst accuracy for Test (R1) } \\
\hline$(1,5,11,12,18,19)$ & 0.5766 & 0.6790 \\
\hline$(1,5,6,7,11,12,19)$ & 0.5766 & 0.6790 \\
\hline$(1,2,5,11,12,19)$ & 0.5766 & 0.6543 \\
\hline$(2,5,11,12,18,19)$ & 0.5766 & 0.6543 \\
\hline$(1,5,12,19,20)$ & 0.5766 & 0.6420 \\
\hline$(2,6,12,17,18)$ & 0.5766 & 0.6420 \\
\hline$(5,6,7,11,12,19)$ & 0.5766 & 0.6420 \\
\hline$(5,6,7,10,12,19,20)$ & 0.5766 & 0.6420 \\
\hline$(1,4,5,9,11,12,13,19)$ & 0.5766 & 0.6420 \\
\hline$(2,5,12,18)$ & 0.5766 & 0.6296 \\
\hline$(2,5,6,7,11,12,17,19)$ & 0.5766 & 0.6296 \\
\hline$(3,5,6,7,12,16,17,19,20)$ & 0.5766 & 0.6296 \\
\hline$(3,5,6,7,8,12,16,17,19,20)$ & 0.5766 & 0.6296 \\
\hline$(5,6,7,17)$ & 0.5766 & 0.6173 \\
\hline$(2,5,6,7,12,19)$ & 0.5766 & 0.6173 \\
\hline$(2,5,6,12,17)$ & 0.5766 & 0.5926 \\
\hline$(5,12,14,17,19)$ & 0.5766 & 0.5926 \\
\hline
\end{tabular}

\subsection{Discussion of the Characteristics of Our Proposed System}

First, we would like to discuss the effectiveness and side effects of our data-augmentation method. As we explained in Sect. 4.2, the system performance using the data-augmentation method is better than one without using this method. To understand the characteristics of this augmentation method, we select the questions whose performance is significantly improved or degraded. The questions shown in Figs.1 and 5 are typical examples of improved or degraded cases. From these examples, we confirm our system tends to focus on logical matching (i.e., the system tends to answer positive (Yes:entail) for the question and article pairs that share the same judicial decision and answer negative (No: not entail) for the flipped pairs). These general characteristics work well when the most relevant article is selected for the question. 


\section{R02-4-I (Answer: entail)}

Question

$\mathrm{A}$ は, B の代理人と称して, $\mathrm{C}$ との間でBの所有 する土地をCに売却する旨の売買契約を締結した が，実際にはその契約を締結する代理権を有して いなかった。Bが売買契約を追認した場合，Aは Cに対する無権代理人の責任を負わない。
$A$, who acts as the agent of $B$, concluded $a$ contract with $C$ for sale of land owned by $B$. However, A had no authority to represent to conclude the contract. If $B$ ratifies the contract of sales, $A$ is not liable to $C$ as an unauthorized agency.

Article
第百十七条 他人の代理人として契約をした者は、 自己の代理権を証明したとき、又は本人の追認を 得たときを除き、相手方の選択に従い、相手方に 対して履行又は損害賠償の責任を負う。
Article 117 (1) A person who concludes a contract as an agent of another person is liable to the counterparty for the performance of the contract or compensation for loss or damage, as chosen by the counterparty, unless the person proves the authority to represent or the principal ratifies the contract.

Fig. 5 Examples of a degraded question

Table 9 Number of models with correct answer classified by types of question

\begin{tabular}{lll}
\hline $\begin{array}{l}\text { Number of models with correct } \\
\text { answer }\end{array}$ & Anonymized & Other \\
\hline $0-3$ & 6 & 4 \\
$4-7$ & 6 & 6 \\
$8-12$ & 4 & 8 \\
$12-15$ & 7 & 4 \\
$16-20$ & 12 & 24 \\
\hline
\end{tabular}

We also would like to analyze the characteristics of our system using failure analysis. As the Task 4 organizers indicated, there are two types of questions. One is a question about the article(s) mostly using the vocabulary of the articles, and the other is a question about the use case that uses anonymized symbols (such as "A" and "B") for referring to persons or organizations. These questions are comparatively more difficult than other questions. In the R2 test data set, we have 35 questions that have such symbols.

Table 9 shows the number of models (out of 20 generated models) that can generate correct answers while considering the question types. The average numbers of correct answer models are 11.8 and 13.7 for anonymized questions and others, respectively.

To analyze the difficulty of the problem, it is necessary to take into account the effect of answering correctly by chance. Even though the system cannot find any good clues to estimate whether the statement is true or false, the system can answer positive or negative and may get the correct answer by chance. Therefore, it is difficult to analyze the results of questions whose number of correct answer models is around half (8-12).

In this paper, we analyze questions with a smaller number of correct answer models to understand how the system tends consistently to answer incorrectly. 


\section{R02-25-E (Answer: not entail)}

Question

賃借人が適法に賃借物を転貸し, その後, 賃貸人 が貨借人との間の貨貸借を合意により解除した場 合, 賃貸人は, その解除の当時, 賃借人の債務不 履行による解除権を有していたときであっても, その合意解除をもって転借人に対抗することはで きない。
If the lessee lawfully subleases a leased thing, the lessor may not duly assert against the sublessee the cancellation by agreement of the lease with the lessee even if the lessor has a right to cancel due to non-performance on the part of the lessee at the time of the cancellation.

Article

第六百十三条 3 賃借人が適法に貨借物を転貸し た場合には、貨貸人は、貨借人との間の貨貸借を 合意により解除したことをもって転借人に対抗す ることができない。ただし、その解除の当時、賃 貸人が貨借人の債務不履行による解除権を有して いたときは、この限りでない

Article 613 (3) If the lessee lawfully subleases a leased thing, the lessor may not duly assert against the sublessee the cancellation by agreement of the lease with the lessee; provided, however, that this does not apply if, at the time of the cancellation, the lessor has a right to cancel due to non-performance on the part of the lessee.

Fig. 6 Examples of the failure for a difficult question (1)

R02-23-U (Answer: not entail) Question

A B 間において A の所有する中古の時計甲の売買 契約が締結された場合、Bが, $\mathrm{E}$ との間で, 売買 契約における買主たる地位を $\mathrm{E}$ に譲渡する旨の合 意をした場合, Aの承諾の有無にかかわらず, 買 主たる地位は $\mathrm{E}$ に移転する。

第五百三十条の二 契約の当事者の一方が第三 者との間で契約上の地位を譲渡する旨の合意をし た場合において、その契約の相手方がその譲渡を 承諾したときは、契約上の地位は、その第三者に 移転する。
If $B$ makes an agreement with $E$ to transfer contractual status of the buyer to $E$, regardless of whether A consents, the status of the buyer is transferred to $\mathrm{E}$.

\section{Article}

Article 539-2 If one of the parties to a contract made an agreement with a third party to transfer that party's contractual status to that third party, and the other party to the contract gives consent to the transfer, the contractual status is transferred to the third party.

Fig. 7 Examples of the failure for a difficult question (2)

The following question (Fig. 6: correctly answered by one model) is a typical question that almost no model can answer correctly. This article has a sentence about exceptional cases ( “ただし、へときは、この限りでない”(“however, this does not apply ...”)). To understand the meaning correctly, it is necessary to check whether the exceptional condition is satisfied, and if such condition is satisfied, it is necessary to flip the judicial decision. Because our data-augmentation method does not use such exceptional case sentences for training as introduced in Sect. 3.1, the system has difficulty handling such an exceptional sentence. As a result, the systems tend to say positive (entail) for this question because many terms appear in both the question and the first sentence and there is no explicit explanation on the flipped decision (i.e., “対抗することができる” (“may duly assert”)). However, because several articles have such exceptional cases, it may be better to propose a data-augmentation method to handle such articles.

The following failure example (Fig. 7: correctly answered by zero models) is related to the logical expression and semantic mismatch. The article says "the 
R02-19-I (Answer: not entail)

Question

保証人は, 被担保債権の一部を弁済したが残債務 がある場合，その弁済をした価額の限度において， 代位により取得した被担保債権及びその担保権を 単独で行使することができる。

If a guarantor has partially paid a secured claim but there is a remaining obligation, the guarantor may independently exercise the secured claim and the security right acquired through subrogation in proportion to the value of the subrogee's performance. Article

第五百二条 債権の一部について代位弁済があっ たときは、代位者は、債権者の同意を得て、その 弁済をした価額に応じて、債権者とともにその権 利を行使することができる。

Article 502 (1) If performance by subrogation occurs with respect to one part of a claim, the subrogee, with the consent of the obligee, may exercise the rights of the subrogee together with the obligee in proportion to the value of the subrogee's performance.

Fig. 8 Examples of the failure for a difficult question (3)

other party to the contract gives consent" (require consent), but the question says "regardless of whether A consents." Because there are no patterns for handling such logical mismatches in the augmented data, it is comparatively difficult for the system to identify this type of logical mismatch. In addition, the vocabulary used for representing related persons is totally different; "A," "B," and "E" are used for the questions; and "one of the party," "the other party," and "the third party" are used in the article. It is also difficult for the system to estimate the relationship among them.

In such a case, the system tends to compare the juridical decision parts of the question and articles. In this case, questions and articles have the same decision “移 転する” (transferred), and therefore, the system tends to answer positive (Yes:entail). This may be a bias that is affected by the augmented training data.

The following failure example (Fig. 8: correctly answered by six models) is another type of problem related to the logical expression (quantifier). The article says "together with the obligee" (more than two), but the question says "independently" (single). It is not so easy to make a simple data-augmentation method for handling this type of logical mismatch.

Those failure examples show that our system tends to generate final results (positive or negative) using logical matching information; i.e., whether the juridical decision of questions and articles are the same or flipped. One of the reasons why our system achieves better performance in this COLIEE task is that we can use the most relevant article for the question. Because the article is the most relevant one, most of the conditions for the articles are satisfied and comparing judicial decisions is an important part to answer the question appropriately. However, comparing juridical decisions themselves is also an important part of the entailment process, and our data-augmentation method can be applicable for any other type of such logical entailment task.

For future works, it is necessary to pay more attention to the comparison of condition parts. For example, to handle the articles with exceptional cases (Fig. 6) appropriately, it is necessary to check whether an exceptional condition is satisfied or not. For discussing such issues, it is better to propose a data-augmentation method for 
semantic matching cases. However, there are varieties of semantic mismatches for entailment analysis including insufficient condition (a part of the conditions is satisfied, but not all of the conditions are satisfied) and semantic mismatch (explanation about the condition does not match the concept used in the article). Compared with the logical mismatch case augmentation, it is difficult to balance systematic negative case data with good positive and negative cases. However, golden standard data (question and article pairs) may be helpful to discuss the type of these mismatches.

In addition, our system relies greatly on the quality of the relevant article. For the real use cases, it is not easy to select the most relevant article. So, it is better to have a mechanism to discuss the similarity of the conditions of the question with different articles. This mechanism is important for the real use case (Task 5: utilization of retrieved articles instead of the most relevant article) to determine the most relevant article from the retrieved results.

We also would like to analyze our system in depth by considering the information used for calculating the final output. For example, visualization of attention information may be the next step to analyze the results.

\section{Conclusion}

In this paper, we proposed a data-augmentation method for legal textual entailment using the original civil law articles. These augmented data support BERT fine-tuning processes by increasing the number of training examples for characterizing the logical mismatch. We implemented a BERT-based ensemble legal textual entailment system using these augmented data. This system supports selecting an appropriate ensemble model setting with validation data. We confirmed the effectiveness of the system using COLIEE 2021 Task 4 (textual entailment task), whose accuracy was 0.7037 . This accuracy was the best among all runs. We also discussed the characteristics of the method and future works using failure analysis and additional experiments.

Acknowledgements We thank the organizers of the COLIEE for their efforts in constructing this test data set.

\section{Declarations}

Conflict of Interest On behalf of all authors, the corresponding author states that there is no conflict of interest.

Open Access This article is licensed under a Creative Commons Attribution 4.0 International License, which permits use, sharing, adaptation, distribution and reproduction in any medium or format, as long as you give appropriate credit to the original author(s) and the source, provide a link to the Creative Commons licence, and indicate if changes were made. The images or other third party material in this article are included in the article's Creative Commons licence, unless indicated otherwise in a credit line to the material. If material is not included in the article's Creative Commons licence and your intended use is not permitted by statutory regulation or exceeds the permitted use, you will need to obtain permission directly from the copyright holder. To view a copy of this licence, visit http://creativecommons.org/licen ses/by/4.0/. 


\section{References}

1. Devlin, J., Chang, M. W., Lee, K., \& Toutanova, K. (2019). BERT: Pre-training of deep bidirectional transformers for language understanding. In: Proceedings of the 2019 Conference of the North American Chapter of the Association for Computational Linguistics: Human Language Technologies, Volume 1 (Long and Short Papers), pp. 4171-4186. Association for Computational Linguistics, Minneapolis, Minnesota. https://doi.org/10.18653/v1/N19-1423. https://www.aclweb.org/ anthology/N19-1423.

2. Evans, R., Saxton, D., Amos, D., Kohli, P., \& Grefenstette, E. (2018). Can neural networks understand logical entailment? In: 6th International Conference on Learning Representations, ICLR 2018, Vancouver, BC, Canada, April 30 - May 3, 2018, Conference Track Proceedings. OpenReview.net. https://openreview.net/forum?id=SkZxCk-0Z.

3. Kano, Y., Kim, M. Y., Goebel, R., \& Satoh, K. (2017). Overview of coliee 2017. In: K. Satoh, M.Y. Kim, Y. Kano, R. Goebel, T. Oliveira (eds.) COLIEE 2017. 4th Competition on Legal Information Extraction and Entailment, EPiC Series in Computing, vol. 47, pp. 1-8. EasyChair.

4. Kim, M. Y., Goebel, R., Kano, Y., \& Satoh, K. (2016). Coliee-2016: Evaluation of the competition on legal information extraction and entailment. In: The Proceedings of the 10th International Workshop on Juris-Informatics (JURISIN2016). Paper 11

5. Kim, M. Y., Xu, Y., \& Goebel, R. (2017). Applying a convolutional neural network to legal question answering. In M. Otake, S. Kurahashi, Y. Ota, K. Satoh, \& D. Bekki (Eds.), New Frontiers in Artificial Intelligence (pp. 282-294). Cham: Springer International Publishing.

6. Mikolov, T., Sutskever, I., Chen, K., Corrado, G.S., \& Dean, J. (2013). Distributed representations of words and phrases and their compositionality. In: Advances in neural information processing systems, pp. 3111-3119.

7. Miller, G. A. (1995). WordNet: A lexical database for English. Communications of the ACM, 38(11), 39-41.

8. Min, J., McCoy, R. T., Das, D., Pitler, E., \& Linzen, T. (2020). Syntactic data augmentation increases robustness to inference heuristics. In: Proceedings of the 58th Annual Meeting of the Association for Computational Linguistics, pp. 2339-2352. Association for Computational Linguistics, Online. https://doi.org/10.18653/v1/2020.acl-main.212. https:/www.aclweb.org/anthology/ 2020.acl-main.212.

9. Nguyen, H. T., Vuong, H. Y. T., Nguyen, P. M., Dang, B. T., Bui, Q. M., Vu, S. T., Nguyen, C. M., Tran, V., Satoh, K., \& Nguyen, M. L. (2020). Jnlp team: Deep learning for legal processing. In: The Proceedings of the 14th International Workshop on Juris-Informatics (JURISIN2020), pp. 195-208. The Japanese Society of Artificial Intelligence.

10. Rabelo, J., Goebel, R., Kim, M. Y., Kano, Y., Yoshioka, M., \& Satoh, K. (2021). Summary of the competition on legal information extraction/entailment (coliee). In: Proceedings of the COLIEE Workshop in ICAIL, pp. 1-7.

11. Rabelo, J., Kim, M. Y., Goebel, R., Yoshioka, M., Kano, Y., \& Satoh, K. (2020). COLIEE2020:methods for legal document retrieval and entailment. In: The Proceedings of the 14th International Workshop on Juris-Informatics (JURISIN2020), pp. 114-127. The Japanese Society of Artificial Intelligence.

12. Rabelo, J., Kim, M. Y., Goebel, R., Yoshioka, M., Kano, Y., \& Satoh, K. (2020). A summary of the coliee 2019 competition. In M. Sakamoto, N. Okazaki, K. Mineshima, \& K. Satoh (Eds.), New Frontiers in Artificial Intelligence (pp. 34-49). Cham: Springer International Publishing.

13. Shao, H. L., Chen, Y. C., \& Huang, S. C. (2020). BERT-based ensemble model for the statute law retrieval and legal information entailment. In: The Proceedings of the 14th International Workshop on Juris-Informatics (JURISIN2020), pp. 223-234. The Japanese Society of Artificial Intelligence.

14. Shorten, C., \& Khoshgoftaar, T. (2019). A survey on image data augmentation for deep learning. Journal of Big Data, 6, 1-48. https://doi.org/10.1186/s40537-019-0197-0

15. Taniguchi, R., Hoshino, R., \& Kano, Y. (2019). Legal question answering system using framenet. In K. Kojima, M. Sakamoto, K. Mineshima, \& K. Satoh (Eds.), New Frontiers in Artificial Intelligence (pp. 193-206). Cham: Springer International Publishing. 
16. Yoshioka, M., Kano, Y., Kiyota, N., \& Satoh, K. (2018). Overview of japanese statute law retrieval and entailment task at coliee-2018. In: The Proceedings of the 12th International Workshop on Juris-Informatics (JURISIN2018), pp. 117-128. The Japanese Society of Artificial Intelligence.

Publisher's Note Springer Nature remains neutral with regard to jurisdictional claims in published maps and institutional affiliations.

\section{Authors and Affiliations}

\section{Yasuhiro Aoki $^{1} \cdot$ Masaharu Yoshioka $^{1,2,3,4} \mathbb{( D} \cdot$ Youta Suzuki $^{1}$}

Yasuhiro Aoki

aoki.yasuhiro.k4@elms.hokudai.ac.jp

Youta Suzuki

suzuki@eis.hokudai.ac.jp

1 Graduate School of Information Science and Technology, Hokkaido University, Kita-ku, Sapporo-shi N14 W9, Hokkaido, Japan

2 Faculty of Information Science and Technology, Hokkaido University, Sapporo, Japan

3 Global Station of Big data and cybersecurity, Hokkaido University, Sapporo, Japan

4 Institute for Chemical Reaction Design and Discovery (WPI-ICReDD), Hokkaido University, Sapporo, Japan 